04

\title{
Исследование пробоя вакуумного промежутка после погасания сильноточной дуги в условиях роста напряжения
}

\author{
(C) А.В. Шнайдер, ${ }^{1}$ C.А. Попов, ${ }^{1}$ А.В. Батраков, ${ }^{1,2}$ Е.Л. Дубровская, ${ }^{1,2}$ В.А. Лавринович ${ }^{2}$ \\ ${ }^{1}$ Институт сильноточной электроники СО РАН, \\ 634055 Томск, Россия \\ ${ }^{2}$ Национальный исследовательский Томский политехнический университет, \\ 634034 Томск, Россия \\ e-mail: schneider@Ive.hcei.tsc.ru
}

(Поступило в Редакцию 27 января 2016 г. В окончательной редакции 11 мая 2017 г.)

Исследован пробой вакуумного промежутка после погасания сильноточной вакуумной дуги с последующим нарастанием переходного восстанавливающегося напряжения на промежутке. Определено влияние таких факторов, как скорость роста переходного напряжения, потенциал экрана, окружающий разрядный промежуток, время горения дуги. Установлено, что раннее размыкание контактов приводит к формированию анодного пятна, которое после перехода тока через ноль является источником паров материала электрода в разрядный промежуток, что, в условиях нарастания напряжения на промежутке, приводит к пробою. Слишком позднее размыкание приводит к пробою короткого промежутка из-за сильных электрических полей.

DOI: 10.21883/JTF.2017.12.45202.1746

\section{Введение}

Проблема электрической прочности вакуумного промежутка после погасания дуги и последующего роста напряжения исследуется в первую очередь в связи с использованием данного явления в вакуумных сетевых выключателях. Однако такие исследования актуальны и для сильноточной вакуумной электроники в целом, в частности, для решения проблемы дугообразования при использовании силовой электроники в вакууме, например, в системах электропитания космических аппаратов. Независимо от области применения ключевым параметром является электрическая прочность изолирующего вакуумного промежутка после погасания дуги. Погасание дуги возможно, например, при переходе тока через ноль или при снижении тока ниже уровня тока среза. После отключения тока электрическая прочность промежутка восстанавливается за счет расширения катодного слоя и отхода границы плазмы от катода $[1,2]$. В вакуумных выключателях отключение возможно благодаря прохождению переменного тока промышленной частоты через ноль. При переходе тока через ноль вакуумная дуга гаснет вследствие существования пороговых токов дуги, лежащих в пределах единиц ампер для большинства металлов [3,4]. Причин пробоя вакуумного промежутка после выключения токов короткого замыкания несколько: недостаточно быстрое расширение катодного слоя из-за большой плотности остаточной плазмы после погасания дуги [5], наличие паров материала контакта [6], наличие примесей в материале контактов, состав и структура контактного материала [7-9], наличие в промежутке между контактами расплавленных частиц материала электродов, длительность горения дуги [10,11].

Так, в работе [10] показано, что оптимальное время горения дуги составляет порядка $2.5 \mathrm{~ms}$ при скорости нарастания переходного восстанавливающего напряжения порядка $8.5 \mathrm{kV} / \mu \mathrm{s}$. При данных условиях не наблюдалось ни одного пробоя.

В настоящей работе выполнено экспериментальное исследование причин пробоя вакуумного промежутка при различных конфигурациях разрядного промежутка и окружающего экрана, а также при различных режимах горения разряда.

\section{Методика и эксперимент}

Электрическая схема экспериментального стенда показана на рис. 1. В основе эксперимента лежит двухконтурная схема для синтетических испытаний по Вейлю-Добке [3], имитирующая режим короткого замы-

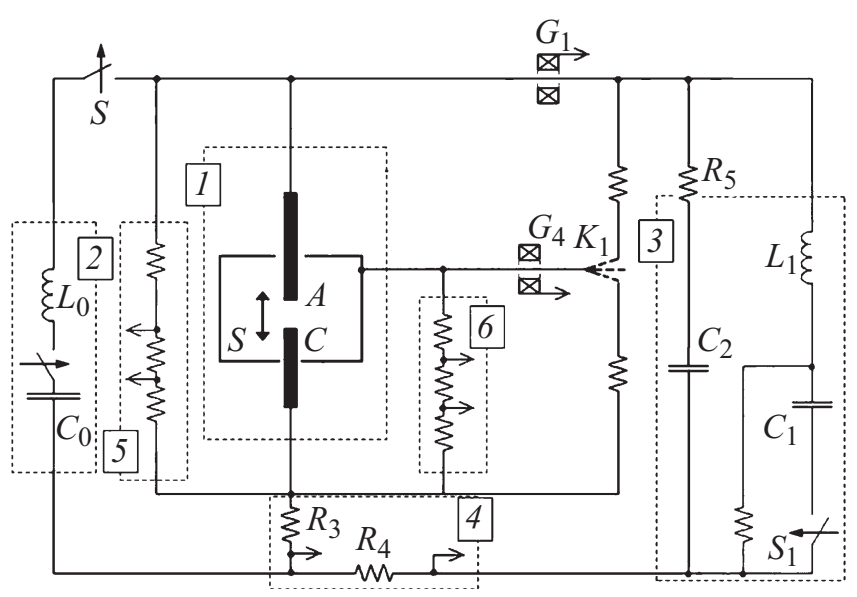

Рис. 1. Схема экспериментальной установки. 1 - вакуумная камера, 2 - источник тока промышленной частоты $(50 \mathrm{~Hz})$, 3 - источник ПВН $(500 \mathrm{~Hz}), 4$ - датчики тока, 5 - датчик напряжения на промежутке, 6 - датчик потенциала экрана, $G_{i}$ - пояса Роговского, $A-$ анод, $C-$ катод, $S-$ экран. 


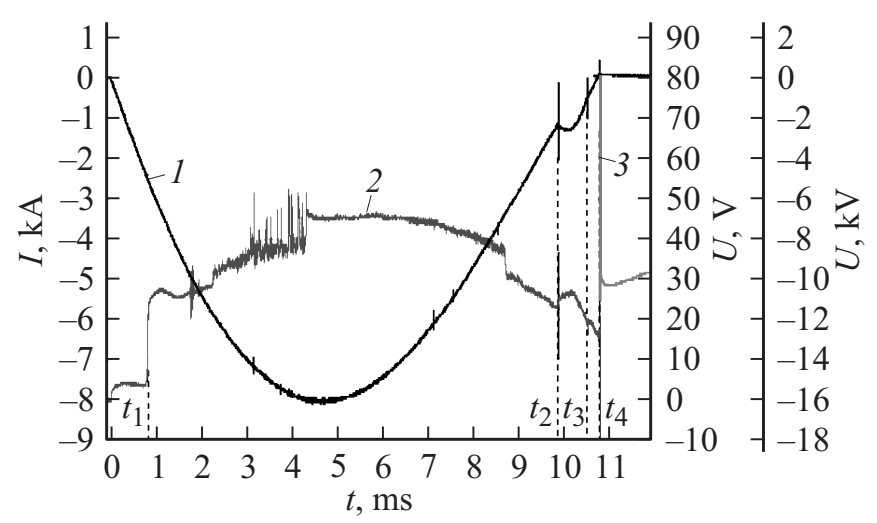

Рис. 2. Осциллограмма тока (1), напряжения (2) и импульса ПВН (3) в вакуумном выключателе VCB. Пример успешного отключения.

кания сети переменного тока промышленной частоты. Низковольтная сильноточная цепь образована индуктивностью $L_{0}=106 \mu \mathrm{H}$, емкостью $C_{0}=75 \mathrm{mF}$ и тиристорным коммутатором $S_{0}$. Форма импульса тока близка к гармонической с длительностью полупериода $10 \mathrm{~ms}$. Максимальная амплитуда тока $50 \mathrm{kA}$ при зарядном напряжении конденсаторной батареи $2.7 \mathrm{kV}$.

Высоковольтная, относительно более слаботочная цепь образована индуктивностью $L_{1}=3.7 \mathrm{mH}$, емкостью $C_{1}=48 \mu \mathrm{F}$ и газонаполненным разрядником-коммутатором $S_{1}$. Данная цепь генерировала гармонический импульс тока длительностью по основанию $1 \mathrm{~ms}$ амплитудой около $1.5 \mathrm{kA}$ (рис. 2, момент времени $t_{2}$ ). Данные параметры схемы обеспечивали скорость спада тока $d I / d t$ к моменту нуля тока, идентичную скорости спада тока в сильноточном контуре. При этом $d I / d t$ оставалась постоянной для различной амплитуды тока разряда и составляла порядка $2 \mathrm{~A} / \mu \mathrm{s}$.

Для разделения высоковольтной и низковольтной цепей служил ключ $S_{2}$ на основе серийного трехфазного вакуумного выключателя.

Все эксперименты проводились при остаточном давлении в вакуумной камере $10^{-5} \mathrm{~Pa}$, которое поддерживалось магниторазрядным насосом со скоростью откачки $2501 / \mathrm{s}$.

Исследуемый вакуумный промежуток образовывался между двумя электродами (контактами) из сплава $\mathrm{CuCr} 25$, содержащего 25\% хрома или чистой безкислородной меди (материалы электродов однотипные), один из которых подвижный, а другой - неподвижный, изолированный с использованием высоковольтного ввода. Скорость движения подвижного контакта составляла $1 \mathrm{~m} / \mathrm{s}$ и выдерживалась практически постоянной на протяжении $10 \mathrm{~ms}$. Для измерения напряжения на контактах вакуумного выключателя использовался активный делитель $R_{0} / R_{1} / R_{2}(13.75 \mathrm{k} \Omega, 500 \Omega, 25 \Omega$ соответственно). Для измерения токов использовались низкоомные шунты $R_{3}=0.1 \mathrm{~m} \Omega$ и $R_{4}=1.9 \mathrm{~m} \Omega$. Вокруг разрядного промежутка располагался экран $S$ диаметром $96 \mathrm{~mm}$, потенциал которого можно было менять с помощью ключа $K_{1}$. Данный экран имитировал экран, установленный в промышленных вакуумных выключателях, который предназначен для предотвращения запыления керамического корпуса вакуумного выключателя.

Работа синтетической схемы в целом проиллюстрирована осциллограммами на рис. 2. Изначально контакты вакуумных выключателей $S_{2}$ и вакуумной камеры замкнуты. После включения тиристора $S_{0}$ начинает нарастать ток генератора низковольтной цепи $L_{0} C_{0}$. В момент времени $t_{1}$ контакты вакуумного выключателя начинают размыкаться. С этого момента в вакуумном выключателе возникает дуговой разряд. Напряжение горения дугового разряда в момент разрыва контактов составляет величину $\sim 20 \mathrm{~V}$, возрастая с нарастанием тока. Контакты трехфазного выключателя $S_{2}$ начинают размыкаться практически в одно время с выключателем $\mathrm{VCB}$. В момент времени $t_{2}$ коммутируется разрядник $S_{1}$, в цепь выключателя VCB подается ток высоковольтной цепи $L_{1} C_{1}$. В момент времени $t_{3}$, когда ток низковольтного контура достигает нуля, полярность на вакуумном выключателе $S_{2}$ меняется, и он восстанавливает свои электроизоляционные свойства, отсекая низковольтный контур. С этого момента ток в выключателе VCB обеспечен только высоковольтным контуром. Момент подачи тока от высоковольтного контура выбирается таким образом, чтобы ток высоковольтной цепи достигал нуля спустя 200-300 $\mu$ s после нуля тока низковольтного контура; за это время плазма в выключателе $S_{2}$ полностью распадается $\left(t_{2} \sim 700 \mu \mathrm{s}\right.$ до окончания полупериода тока низковольтной цепи $\left.t_{3}\right)$.

Переходное восстанавливающееся напряжение (ПВН) обратной полярности возникает на контактах выключателя VCB при переходе этого тока через ноль в момент $t_{4}$. Амплитуда и форма импульса напряжения ПВН определяются параметрами высоковольтного контура.

Эксперименты по исследованию пробоя проводились при различных условиях: разный потенциал экрана, разный материал контактов, разная скорость нараста-

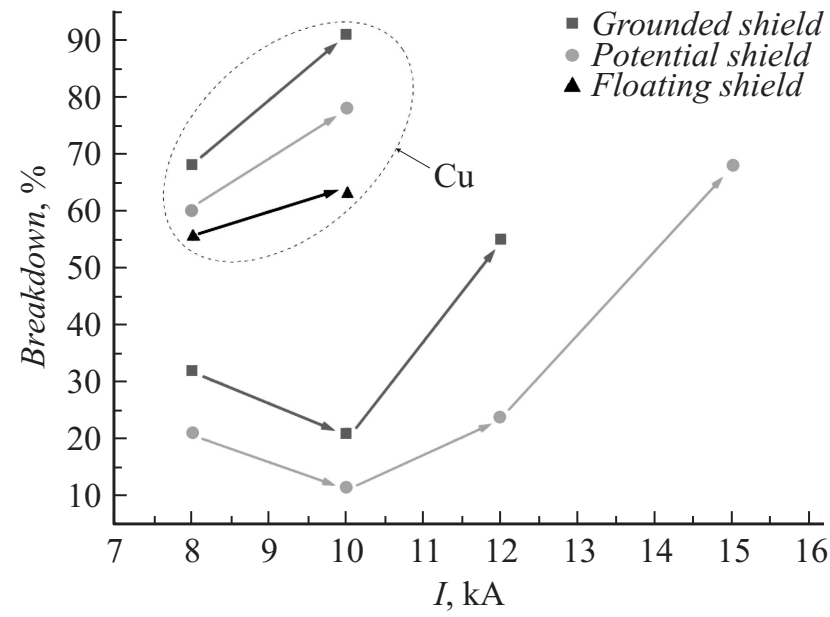

Рис. 3. Зависимость количества пробоев от тока разряда при контактах из $\mathrm{Cu}$ и $\mathrm{CuCr}$ и различном потенциале экрана, окружающего разрядный промежуток. 

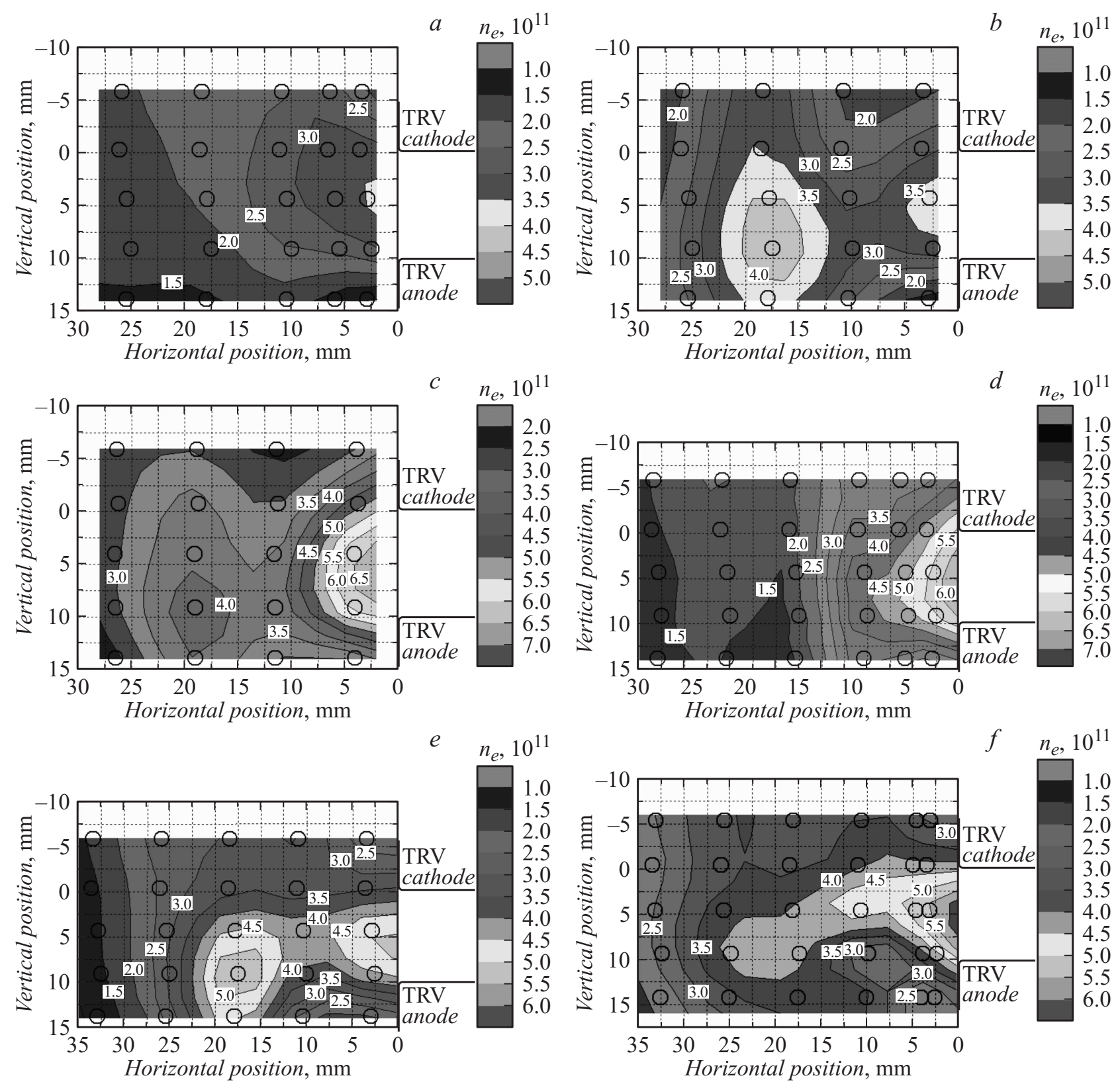

Рис. 4. Распределение концентрации плазмы в межэлектродном промежутке непосредственно в нуле тока. Левый столбец $(a, b, c)-8,10$ и $12 \mathrm{kA}$ при заземленном экране; правый столбец $(d, e, f)-8,10$ и $12 \mathrm{kA}$ при экране под потенциалом ПВН. Кругами обозначено положение зондов.

ния импульса ПВН и длительность горения дугового разряда.

Для восстановления концентрации плазмы в разрядном промежутке после перехода тока через ноль использовался зондовый метод. Электронная концентрация плазмы $n_{e}$, которая соответствует токам на зонды $I_{p}$, может быть оценена по формуле (1):

$$
n_{e}\left(\mathrm{~cm}^{-3}\right) \approx 1.2 \cdot 10^{12} \cdot I_{p}(\mathrm{~A}),
$$

в предположении электронной температуры $k T_{e}=3 \mathrm{eV}$ [12]. Оценки, согласно (1), показывают, что средняя плотность плазмы составляет $n_{e} \sim 9.65 \cdot 10^{11} \mathrm{~cm}^{-3}$ для $8 \mathrm{kA}, \quad n_{e} \sim 2.51 \cdot 10^{12} \mathrm{~cm}^{-3}$ для $10 \mathrm{kA} \quad$ и $n_{e} \sim 5.5 \cdot 10^{12} \mathrm{~cm}^{-3}$ для $12 \mathrm{kA}$ для медных контактов при горении дуги, что совпадает с результатами работ $[1,12]$.

\section{Результаты и их обсуждение}

\section{Зависимость пробоя от тока дуги}

Эксперименты по исследованию зависимости пробоя от амплитуды тока разряда и потенциала экрана проводились для двух типов сплошных контактов без генерации магнитного поля, медных и $\mathrm{CuCr}$, путем 


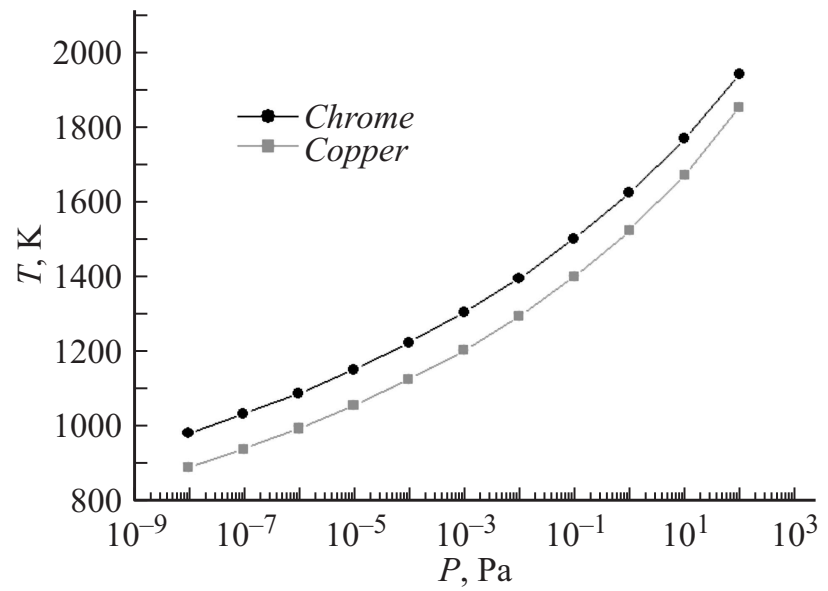

Рис. 5. Зависимость давления насыщенных паров от температуры для хрома и меди.

постепенного повышения амплитуды тока разряда от 8 до $12 \mathrm{kA}$. Результаты представлены на рис. 3.

Видно, что при использовании чисто медных электродов пробои происходят в 2-3 раза чаще при прочих равных условиях. С ростом амплитуды тока вероятность пробоя также увеличивается. Объясняется это тем, что при больших амплитудах токов возрастает тепловая нагрузка на электроды и генерируется более плотная плазма, что подтверждается экспериментальными данными. Кроме того, на медных электродах образуется большее количество капель, летящих в межэлектродном промежутке, которые оказывают значительное влияние на отключающую способность [3,5].

Для $\mathrm{CuCr}$-электродов был обнаружен достаточно интересный режим: с увеличением амплитуды тока происходит сначала улучшение отключающей способности, а затем ее ухудшение. Для анализа этого явления была восстановлена концентрация плазмы межэлектродного промежутка в окрестностях нуля тока с помощью зондового метода и построено двумерное распределение (рис. 4).

Анализ показал (рис. 4), что концентрация плазмы в межэлектродном промежутке в нуле тока примерно одинаковая для 8 и $10 \mathrm{kA}$. Однако отключающая способность при $10 \mathrm{kA}$ немного лучше (рис. 3). Из литературы известно [5], что небольшую положительную роль в отключающей способности играет давление пара. Согласно Кобайну, для успешного прерывания тока плотность пара в промежутке должна быть меньше $10^{15} \mathrm{~cm}^{-3}$. Но даже если плотность пара меньше приведенного значения, пробой может произойти, так как испарение материала электрода может способствовать образованию катодного пятна на бывшем аноде [5]. На рис. 5 представлена зависимость давления пара от температуры. Проведенные ранее исследования [13] показали, что средняя температура поверхности анода составляет $1500 \mathrm{~K}$ для $8 \mathrm{kA}, 1620 \mathrm{~K}$ для $10 \mathrm{kA}$ и $1650 \mathrm{~K}$ для $12 \mathrm{kA}$. Из этих данных и рис. 5 видно, что для температуры 1500 и $1600 \mathrm{~K}$ давление отличается на порядок. Из соотношения $p=n k T$ можно восстановить концентрацию пара в промежутке. Так, для $15 \mathrm{kA}$ дуги давление паров хрома $p(1818 \mathrm{~K}) \sim 20 \mathrm{~Pa}$ (при температуре поверхности анода $1818 \mathrm{~K}$ ) и соответственно $n \sim 7.9 \cdot 10^{14} \mathrm{~cm}^{-3}$. Таким образом, небольшое улучшение отключающей способности для $10 \mathrm{kA}$ в сравнении с $8 \mathrm{kA}$, вероятно, связано с тепловым режимом анода, который влияет на образование пара.

Из рис. 3 видно, что наихудший вариант с точки зрения пробоя - это заземленный экран. Затем идет случай экрана под потенциалом ПВН. В данном случае ситуация немного улучшается в виду того, что отрицательный потенциал экрана способствует эрозии границы плазмы (т.е. собирает ионы на себя). Однако при большом отрицательном потенциале возникает вероятность того, что частицы, адсорбированные экраном, покинут его, ускорятся в поле и в конечном счете вызовут пробой. Когда экран находится под плавающим потенциалом, после перехода тока через ноль он оказывается под небольшим отрицательным потенциалом. В этом случае его поведение похоже на поведение экрана под потенциалом ПВН, т.е. экран вытягивает на себя ионы из плазмы. Однако небольшой потенциал экрана, а следовательно, и поле не позволяют развиваться пробою с экрана.

Кроме того, проводились исследования влияния скорости нарастания импульса ПВН на количество пробоев разрядного промежутка. Скорость нарастания ПВН $d U / d t$ (форма переднего фронта ПВН) изменялась путем подбора резистора $R_{5}$ и емкости $C_{2}$. При этом основная индуктивность $L_{1}$, емкость $C_{1}$ и зарядное напряжение высоковольтной цепи не менялись. Таким образом, скорость спада тока $d I / d t$ вблизи перехода тока через ноль была одинаковой и составляла порядка $2 \mathrm{~A} / \mu \mathrm{s}$.

Результаты экспериментов приведены на рис. 6, $a$ для $8 \mathrm{kA}$ и рис. $6, b$ для $10 \mathrm{kA}$ для случая медных электродов и при различном потенциале экрана. Видно, что с увеличением скорости нарастания ПВН количество пробоев увеличивается в среднем на 10\% для экрана под плавающим потенциалом и потенциалом ПВН. С увеличением скорости нарастания ПВН увеличивается как напряженность поля в катодном слое $(E)$, так и средняя скорость движения границы катодного слоя $\left(v_{b}\right)$. Однако рост напряженности поля в слое превосходит рост скорости движения плазмы (таблица) [12]. Достаточно

Параметры расширяющегося катодного слоя для различных амплитуд тока дуги и скорости нарастания импульса ПВН

\begin{tabular}{c|c|c|c|c|c}
\hline \multirow{2}{*}{$I, \mathrm{kA}$} & $\begin{array}{c}d U / d t, \\
\mathrm{kV} / \mu \mathrm{s}\end{array}$ & $\begin{array}{c}v_{b}, \times 10^{4}, \\
\mathrm{~cm} / \mathrm{s}\end{array}$ & $\begin{array}{c}E, \\
\mathrm{kV} / \mathrm{cm}\end{array}$ & $v_{b 0.8} / v_{b 0.4}$ & $E_{0.8} / E_{0.4}$ \\
\hline \multirow{2}{*}{8} & 0.4 & 6.7 & 5.7 & \multirow{2}{*}{1.3} & 1.61 \\
\cline { 2 - 4 } & 0.8 & 8.7 & 9.2 & & \\
\hline \multirow{2}{*}{10} & 0.4 & 5.6 & 7 & \multirow{2}{*}{1.2} & \multirow{2}{*}{1.66} \\
\cline { 2 - 4 } & 0.8 & 6.7 & 11.6 & &
\end{tabular}



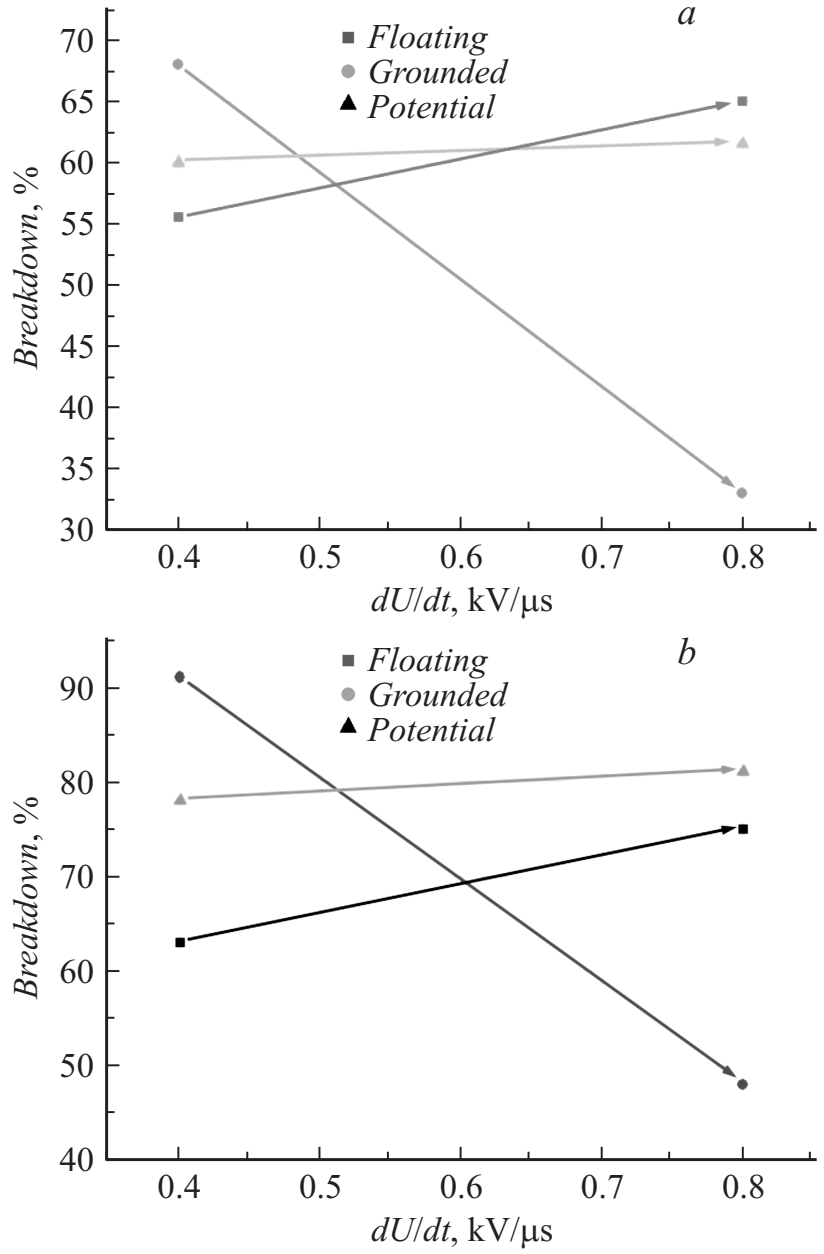

Рис. 6. Зависимость количества пробоев от скорости роста ПВН при различном потенциале экрана, окружающего разрядный промежуток. $a$ - для тока $8 \mathrm{kA}$ и $b-$ для $10 \mathrm{kA}$ для случая медных электродов.

интересный случай получился для заземленного экрана: с увеличением скорости ПВН количество пробоев уменьшалось. Анализ показал, что причина такого поведения связана с плотностью плазмы в течение горения дуги. В случае $0.8 \mathrm{kV} / \mu \mathrm{s}$ плотность плазмы оказалась меньше.

\section{Влияние времени горения дуги}

В данной серии экспериментов исследовалось влияние длительности горения дугового разряда на отключающую способность. Эксперименты проводились следующим образом: при достижении зарядного напряжения включался тиристор $S_{0}$ и через контакты камеры начинал протекать ток. В некоторый момент времени $t_{0}$, задаваемый оператором, после начала протекания тока подвижный контакт начинал двигаться, и в промежутке загоралась электрическая дуга. В дальнейшем изменялось только время начала размыкания контактов $t_{0}$.

Типичная осциллограмма тока через вакуумную дугогасительную камеру (ВДК) в серии экспериментов с амплитудой тока $11 \mathrm{kA}$ и соответствующего этому току напряжения горения дуги показана на рис. 7. Изменение момента $t_{0}$ не влияло на форму тока через ВДК, в то время как напряжение на выводах контактов значительно зависело от момента начала размыкания.

При времени размыкания контактов до $2 \mathrm{~ms}$ $\left(t_{0}<2 \mathrm{~ms}\right)$ стабильно от импульса к импульсу наблю-

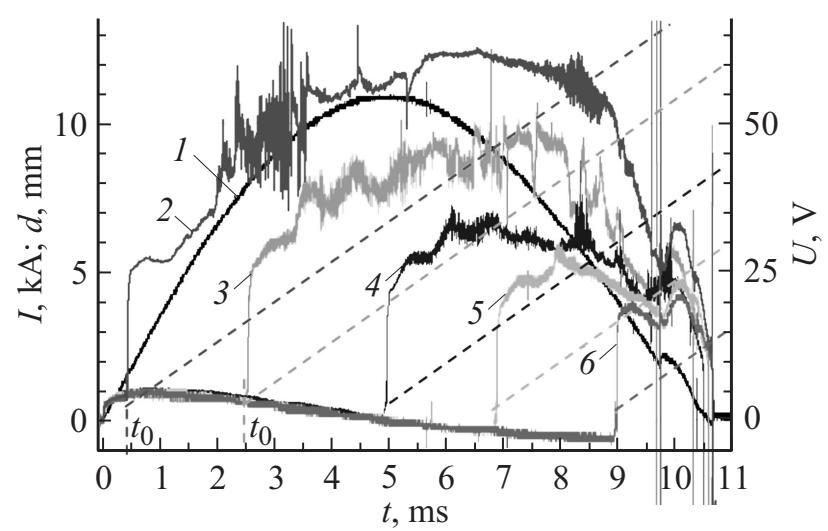

Рис. 7. Осциллограмма тока через ВДК (кривая 1) и осциллограмма напряжения горения дуги (кривые 2-6) при различных значениях момента размыкания контактов, а также динамика изменения соответствующих межконтактных расстояния, $t_{0}-$ начало движения подвижной контакт детали, штрихами показан межэлектродный зазор.
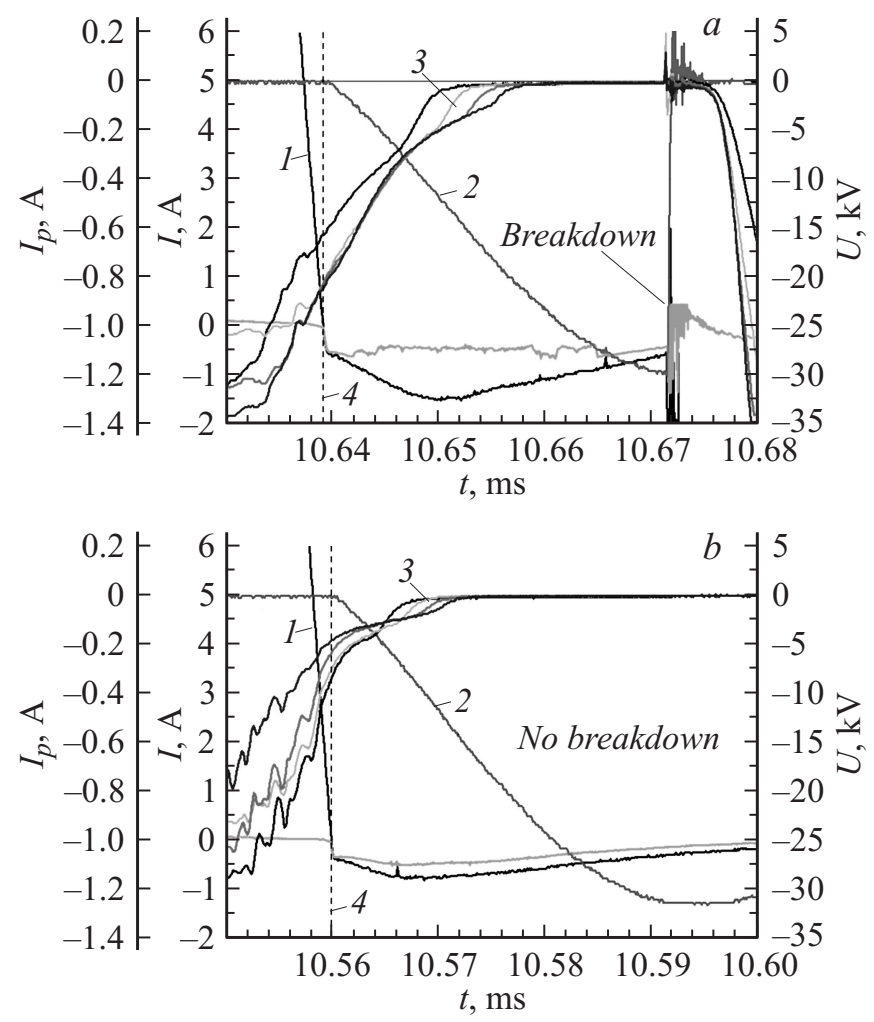

Рис. 8. $a-$ осциллограммы тока $I(1)$, переходного восстанавливающегося напряжения (ПВН) (2), а также токов на зонды $I_{p}(3)$ вблизи перехода тока через ноль (4) для случая „раннего“ размыкания контактоу $t_{0}=0.4 \mathrm{~ms}$ и $b-$ для случая размыкания контактов $t_{0}=3.5 \mathrm{~ms}$. 


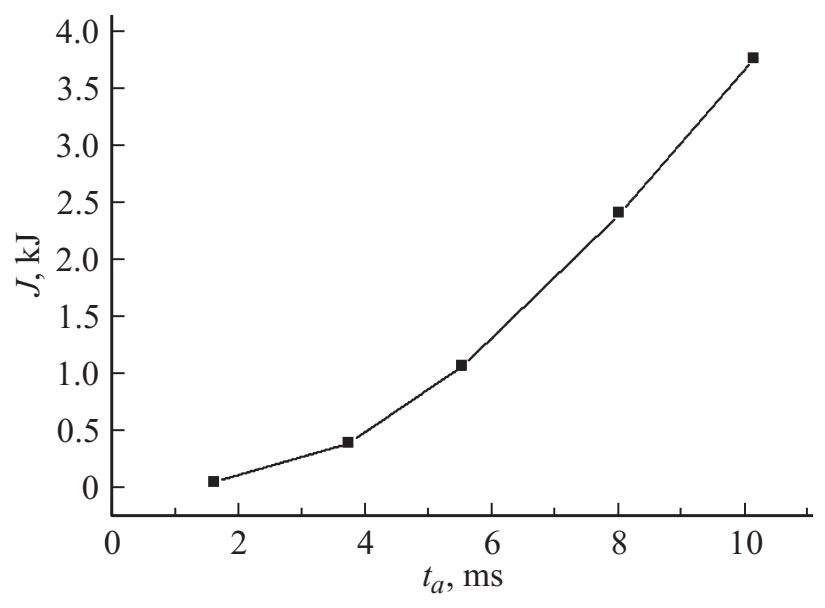

Рис. 9. Зависимость выделения энергии $J$ в межэлектродном промежутке от времени горения дуги $t_{a}$ для амплитуды тока дуги $11 \mathrm{kA}$.

дались пробои при приложении ПВН (рис. 8,a). При увеличении $t_{0}$ от 2 до $3 \mathrm{~ms}$ вероятность пробоев резко уменьшалась. Уже при $t_{0}=3.5 \mathrm{~ms}$ пробои не наблюдались. Типичные осциллограммы для случая $t_{0}=3.5 \mathrm{~ms}$ представлены на рис. $8, b$.

Пробоя при приложении ПВН не наблюдалось до увеличения $t_{0}$ до момента, когда до перехода тока через ноль оставалась чуть меньше $1 \mathrm{~ms}$. При этом напряженность электрического поля достигала порядка $300 \mathrm{kV} / \mathrm{cm}$. При дальнейшем приближении $t_{0}$ к моменту перехода тока через ноль возникали пробои.

Из представленных выше данных видно, что момент начала размыкания контактов $t_{0}$ сильно влияет на характер протекающих в вакуумной дугогасительной камере физических процессов и на отключающую способность промежутка.

Ключевым фактором, влияющим на пробой межконтактного промежутка при приложении ПВН, является высокая плотность плазмы и паров материала анода, основным источником которых к моменту перехода тока через ноль является высокая температура анода и формирование анодного пятна. Выделение энергии в разряде существенно зависит от момента $t_{0}$ и обусловлено влиянием на этот процесс нескольких факторов. Во-первых, $t_{0}$ связано с длительностью горения дуги до перехода тока через ноль - чем раньше размыкаются контакты, тем выше длительность горения дуги, т.е. выше энерговыделение, рассчитанное из осциллограмм тока и напряжения (рис. 9). Во-вторых, при раннем размыкании длиннее межэлектродный зазор и в условиях амплитуд токов выше критических это способствует контрагированию разряда. Контрагирование приводит к росту напряжения горения дуги, т. е. к увеличению выделяемой мощности. Кроме того, контрагирование разряда означает концентрацию теплового воздействия на поверхности анода, т.е. к дополнительному росту плотности выделяемой энергии. Эти механизмы особенно актуальны для сплошных контактов, без генерирования аксиальных магнитных полей за счет протекающего тока.

\section{Заключение}

Показано влияние цилиндрического экрана и его потенциала на отключающую способность. Наиболее благоприятные условия достигаются при плавающем потенциале экрана.

Исследовано влияние скорости нарастания ПВН на количество пробоев в разрядном промежутке камеры. С увеличением роста ПВН увеличивается как скорость движения границы плазмы, так и напряженность поля в катодном слое. Рост напряженности поля превосходит рост скорости расширения слоя, поэтому наблюдается ухудшение отключающей способности порядка $10 \%$.

Продемонстрировано влияние длительности горения дуги на отключающую способность вакуумного выключателя. Основным фактором пробоя является наличие плазмы концентрации более $10^{12} \mathrm{~cm}^{-3}$ в межконтактном промежутке и пары материала анода, источником которых является высокая температура анода и формирование анодного пятна. С этой точки зрения необходимо отодвигать время разведения контактов ближе к переходу тока через ноль, тем самым уменьшать выделение мощности на аноде. Уменьшение длительности горения дуги также приводит к уменьшению эрозии контактов, что положительно сказывается на ресурсе выключателя. Однако при малых межэлектродных расстояниях необходимо учесть вероятность пробоя за счет сильного электрического поля порядка $300 \mathrm{kV} / \mathrm{cm}$.

\section{Список литературы}

[1] Sarrailh P. et al. // J. Phys. D: Appl. Phys. 2008. Vol. 41.

[2] Duning G., Lindmayer M. // Proc. 18th Int. Symp. Discharges and Electrical Insulation in Vacuum. Eindhoven, The Netherlands, 1998. P. 447.

[3] Slade P.G. The Vacuum Interrupter. Theory, Design, and Application. NY.: CRC Press, 2008. Ch. 2.

[4] Кесаев И.Г. Катодные процессы электрической дуги. М.: Наука, 1968.

[5] Вакуумные дуги / Под ред. Дж. Лафферти. М.: Мир, 1982. $432 \mathrm{c}$.

[6] Sarrailh P. et al. // Plasma Sources Sci. Technol. 2010. Vol. 19.

[7] Rieder W.F., Schussek M., Glatzle W., Kny E. // IEEE Trans. CHMT. 1989. Vol. 12. N 2. P. 273-278.

[8] Wang Y., Ding B. // IEEE Trans CPMT. 1999. Vol. 22. N 2. P. 467-472.

[9] Ding B., Yang Z., Wang X. // IEEE Trans. CPMT. 1996. Vol. 19. N 1. P. 76-81.

[10] Kaumanns J. // Proc. XVIII ISDEIV. 1998. P. 492-495.

[11] Zalucki Z., Seidel S., Kutzner J. // Proc. 3th Int. Symp. Discharges and Electrical Insulation in Vacuum. Paris, France. 1968. P. 358.

[12] Schneider A.V., Popov S.A., Batrakov A.V., Sandolache G., Rowe S.W. // IEEE Trans. Plasma Sci. 2011. Vol. 39. N 6. P. 1349-1353.

[13] Schneider A.V., Popov S.A., Batrakov A.V., Sandolache G., Schellekens H. // IEEE Trans. Plasma Sci. 2013. Vol. 41. N 8. P. 2022-2028. 